\title{
Anorectal melanoma metastatic to the breast: a case report and review of the literature
}

\author{
This article was published in the following Dove Press journal: \\ OncoTargets and Therapy \\ 10 August 2016 \\ Number of times this article has been viewed
}

\author{
Liang Feng' \\ Dian-Jun $\mathrm{Qi}^{2}$ \\ Qing-Fu Zhang ${ }^{3}$ \\ 'Department of Breast Surgery, \\ The First Affiliated Hospital of China \\ Medical University, Shenyang, People's \\ Republic of China; ${ }^{2}$ Department of \\ General Practice, The First Affiliated \\ Hospital of China Medical University, \\ Shenyang, People's Republic of China; \\ ${ }^{3}$ Department of Pathology, The First \\ Affiliated Hospital of China Medical \\ University, College of Basic Medical \\ Sciences of China Medical University, \\ Shenyang, People's Republic of China
}

Correspondence: Qing-Fu Zhang Department of Pathology, The First Affiliated Hospital of China Medical University, College of Basic Medical Sciences of China Medical University, Number 155 Nanjing North Street, Heping District, Shenyang I I000I, People's Republic of China Email qfzhang@cmu.edu.cn

\begin{abstract}
Melanoma develops from melanocytes and typically occurs on the skin and mucosa with a high degree of malignancy. Intensive local invasion and distant metastasis of melanoma result in poor patient prognosis, owing to frequent metastases to the lungs, bones, brains, and other parts of the body. In the present study, we report a case of anorectal melanoma in a 56-yearold woman who was admitted to our hospital because of local recurrence 9 months after local resection. She subsequently underwent radical surgery. Metastasis to the left breast occurred within 4 months after radical surgery. Metastasis of anorectal melanoma to the breast is very rare. In the present case report and literature review, we analyzed the clinical manifestation, diagnosis, and treatment of anorectal melanoma metastatic to the breast.
\end{abstract}

Keywords: melanoma, breast, metastasis

\section{Introduction}

Melanoma is a highly malignant skin tumor caused by the excessive proliferation of atypical melanocytes and frequently occurs on the skin of the trunk and four limbs or in the mucosal layer close to the skin. The incidence of melanoma in the People's Republic of China is low; however, it has been increasing in the recent years. More than $90 \%$ of the melanoma cases involve the skin tissues. ${ }^{1,2}$ Primary anorectal melanoma is relatively less common compared to the melanoma of other body parts. In addition, metastases of malignant tumors to the breast tissue are uncommon; the patient in the present study represents the fifth case reported in the English literature.

\section{Case report}

A 55-year-old woman was initially diagnosed with "mixed hemorrhoids" at the Shenyang Proctology Hospital (Liaoning, People's Republic of China) with complaints of intermittent blood in the stool with tenesmus for 1 month. She underwent surgical resection, and postoperative paraffin pathology confirmed anorectal melanoma. However, the patient refused radical surgery and other treatment options. After 9 months, the patient developed a local recurrence. She was admitted to the Department of Surgical Oncology of The First Affiliated Hospital of China Medical University. Colonoscopy showed a smooth mucosa with a polypoid bulge of $\sim 1.0 \times 0.8 \mathrm{~cm}$ in size, located $6 \mathrm{~cm}$ close to the anal verge, without any erosion, ulcer, hemorrhage, or necrosis (Figure 1). Microscopic examination showed diffusely distributed, small, and relatively uniform tumor cells with oval-shaped, deviated nuclei and deep staining (Figure 2A). The tumor cells resembled plasma cells, showing evidence of mitosis and less cytoplasm without clear pigmentation (Figure 2B). The results of the immunohistochemistry analyses performed using specific markers to confirm 


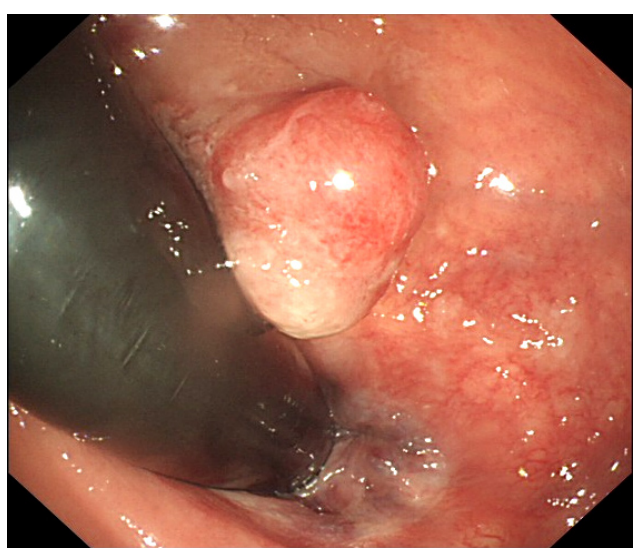

Figure I Endoscopic findings: proctoscopy revealed a mass at the anorectal junction.

small-cell melanoma were as follows: cytokeratin (pan, - ), synaptophysin (-), chromogranin A (-), CD20 (-), Pax-5 $(-), \operatorname{CD} 3(-), \operatorname{CDX} 2(-), \operatorname{CD} 15(-)$, S-100 (+; Figure 2C); vimentin (+; Figure 2D), HMB-45 (+), Melan-A (+), CD56 $(+)$, CD138 (-), CD38 (-), MUM1 (-), and a Ki67 index of $\sim 60 \%$. Thus, the tumor was confirmed as small-cell melanoma. The patient underwent abdominoperineal resection. There was no metastasis to the regional lymph nodes (zero of eleven nodes); however, a single stage IIIC nodular melanoma with the TNM classification pT4bN1bM0 was found in the drainage region of lymph nodes. The patient still refused chemotherapy and radiotherapy; however, 40 days after surgery, she received biological therapy consisting of dendritic cells combined with cytokine-induced killer cells.

A tumor was detected in the left breast via ultrasonography after 4 months of radical surgery. Breast ultrasonography showed a hypoechoic region in the outer upper quadrant of the left breast sized $1.46 \times 1.26 \mathrm{~cm}^{2}$ (Figure 3A). The mass had atypical characteristics and strip-shaped blood flow around the edges (Breast Imaging Reporting and Data System 4C; Figure 3B). The pathological examination of the specimen obtained via fine needle aspiration biopsy using a hollow needle showed morphological findings consistent with anorectal melanoma (Figure 4A). The immunohistochemistry results were as follows: cytokeratin (pan, - ), vimentin (+; Figure 4B); S-100 (+), Melan-A (+; Figure 4C); HMB-45 (+; Figure 4D); CD3 (T lymphocytes, +), CD20 (B lymphocytes, +), Pax-5 (B lymphocytes, +), chromogranin A (-), synaptophysin (-), CD138 (-), ER (-), Her2 (-), P63 (-), GATA-3 (-), and a Ki67 index of $\sim 70 \%$, which confirmed anorectal melanoma metastatic to the breast.

\section{Discussion}

Anorectal melanoma frequently occurs near the dentate line. As the tumor is highly invasive and lymphatic vessels are abundant near the dentate line, local spread and distant metastases may occur in the early phase of the disease, with a $1.2 \%$ metastasis rate to the breast, resulting in a 5 -year overall survival of $<20 \% .^{3-6}$ In the present study, 30 cases of melanoma metastatic to the breast that were reported from 1995 to 2015, including the present case, were reviewed retrospectively. ${ }^{7-23}$ The mean patient age was 54 years, and $87.1 \%$ of the patients were women. The most common primary sites of melanoma were the skin tissues of the trunk (28.6\%, eight out of 28 patients) and head and face $(28.6 \%$, eight out of 28 patients). Including the patient reported in the present study, only five patients were previously reported to have anorectal melanomas metastatic to the breast. Two of the patients died 3 months after metastasis to the breast. The average survival time after metastasis was $>12.5$ months.

In 1984, $\mathrm{Lee}^{24}$ showed that melanoma cells expressed estrogen receptors; however, the role of estrogen in the metastases to the breast is presently controversial. An association was previously reported between metastasis of melanoma to the breast and menopausal status. Arora and Robinson ${ }^{25}$ reported 15 patients with melanomas that metastasized to the breast, of which $93 \%$ were premenopausal. Another retrospective study involving 27 cases also reported that $70 \%$ of the patients were at the premenopausal
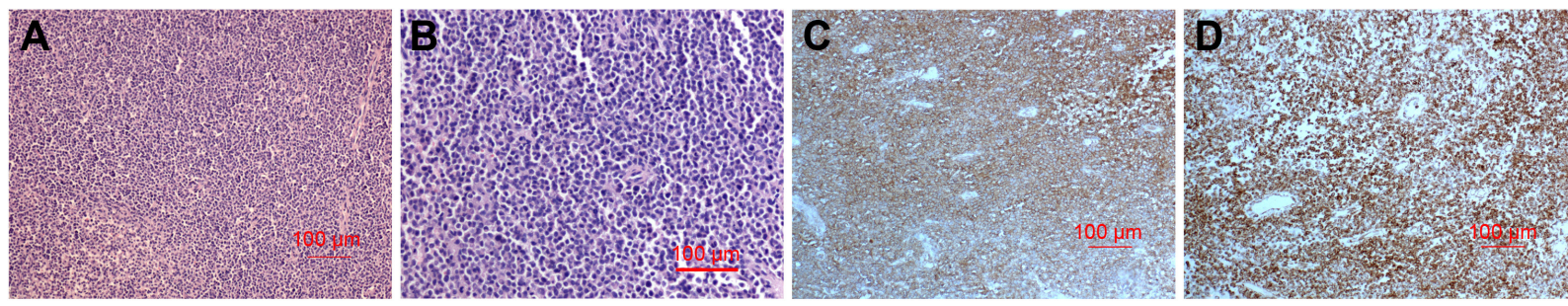

Figure 2 Hematoxylin and eosin immunohistochemical staining findings for the primary tumors are shown.

Notes: (A) Smaller tumor cells with a diffuse distribution are observed in the anal tumor; hematoxylin-eosin stain, $\times 100$. (B) High magnification microscopy showing a tumor cell morphology similar to that of plasma cells. The nuclei displayed atypia and conspicuous mitotic activity. (C) Tumor cells showing positive staining for S-100; immunohistochemistry staining, $\times 100$. (D) Tumor cells showing diffuse positive staining for vimentin; immunohistochemistry staining, $\times 100$. 

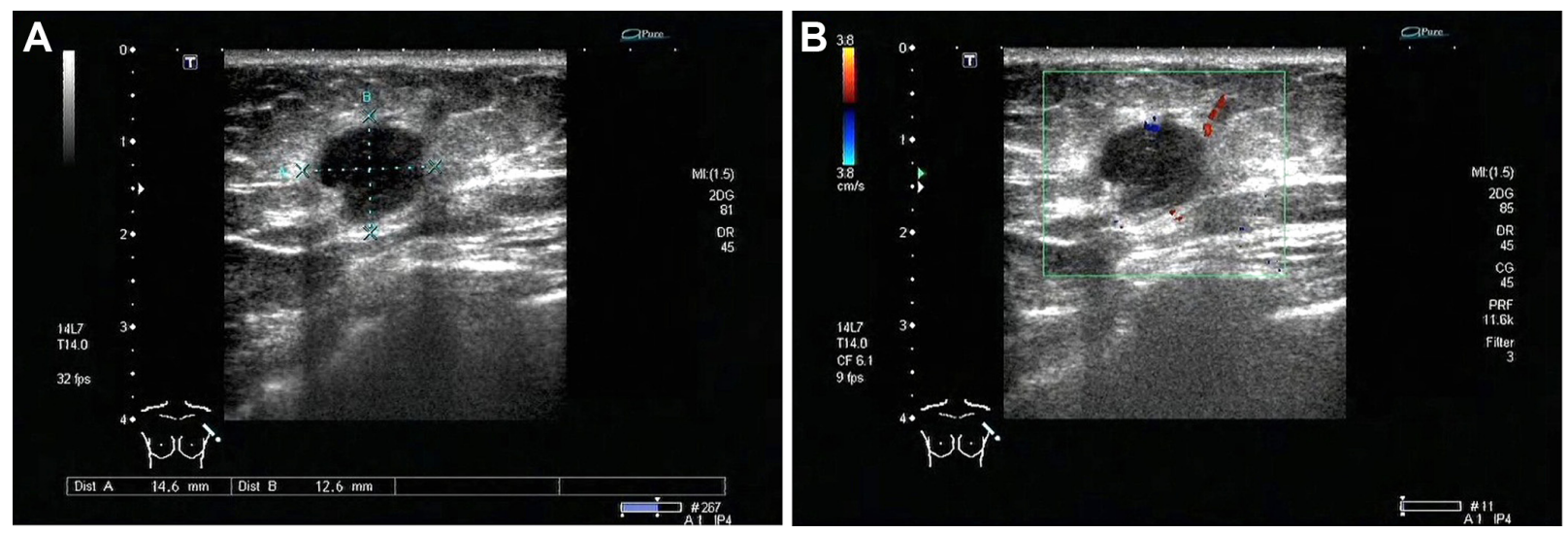

Figure 3 Breast ultrasonography images.

Notes: (A) A hypoechoic region sized $1.46 \times 1.26 \mathrm{~cm}$ is seen in the outer upper quadrant of the left breast. (B) The mass has atypical characteristics and strip-shaped blood flow around the edges (BI-RADS 4C).

Abbreviation: BI-RADS, Breast Imaging Reporting and Data System.

stage. ${ }^{6}$ The breast tissue of older patients is more fibrous, and the relatively poor blood supply makes the environment unfavorable for metastasis in these patients. Arora and Robinson ${ }^{25}$ suggested a direct role for estrogen in facilitating metastatic spread.

The inhibition of antitumor immune responses in human beings is associated with metastatic melanoma. ${ }^{26,27}$ Jayaraman et $\mathrm{a}^{28}$ found, in a mouse model of melanoma, that the number of Treg cells increased in the peripheral blood of mice with metastatic melanoma and that the inhibition of Treg induction could effectively prevent the proliferation of tumor cells. The interactions of tumor cells with the microenvironment and the immune system are significant in the infiltration and metastasis of melanoma. In the clinical setting (Table 1), the average time from the diagnosis of the primary tumor to its metastasis to the breast was 49.9 months. Frequently, the tumors were identified as single lesions sized $0.8-6.0 \mathrm{~cm}$. Primary tumors mostly involve the outer upper quadrant, consistent with the predilection sites for breast cancer. ${ }^{29}$ The therapeutic principle used for the treatment of melanoma metastatic to the breast tissue does not differ from that of melanoma metastatic to other sites. ${ }^{30}$ The standard therapeutic approach remains surgery supplemented with radiotherapy, chemotherapy, immunotherapy, and other treatments. In the present study, the retrospective analysis showed that almost one-third of the patients received radical mastectomy after the metastasis of melanoma, whereas approximately half of them preferred radiotherapy and chemotherapy as adjuvant therapies for the treatment of metastases to the breast.

Most melanoma patients with metastases to the breast already have local spread and metastases to multiple other organs that commonly include the epithelial tissues, lungs, brain, and liver. ${ }^{6,31,32}$ We identified six out of 16 patients $(37.5 \%)$ with metastases to other tissues and organs in addition to the breast. Metastasis to the breast is an indicator of poor prognosis. ${ }^{33}$ Ravdel et $\mathrm{al}^{6}$ reported that the median survival time of 27 patients who had melanomas metastasized to the breast was 12.9 months. In the present study, we reviewed eight of 15 patients who died within 1 year after metastasis to the breast. The patient in the present study refused chemotherapy after metastasis to the breast. To date,
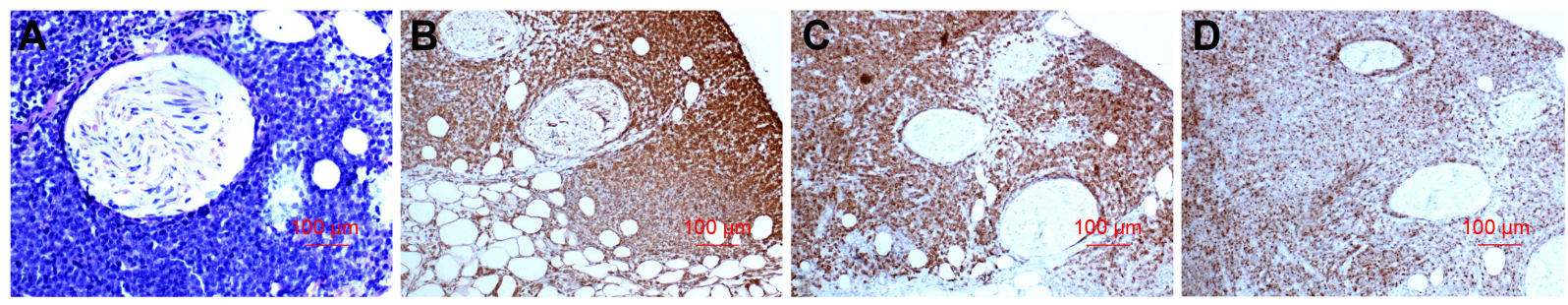

Figure 4 Immunohistochemical staining findings for the metastatic tumors are shown.

Notes: (A) Metastatic tumor in the left breast showing morphological findings consistent with those of the anorectal melanoma; immunohistochemistry staining, $\times 100$. (B) Metastatic tumor cells showing positive staining for vimentin; immunohistochemistry staining, $\times 100$. (C) Metastatic tumor cells showing positive staining for Melan-A; immunohistochemistry staining, $\times 100$. (D) Metastatic tumor cells showing positive staining for Hmb45; immunohistochemistry staining, $\times 100$. Scale bar, I00 $\mu$ m. 


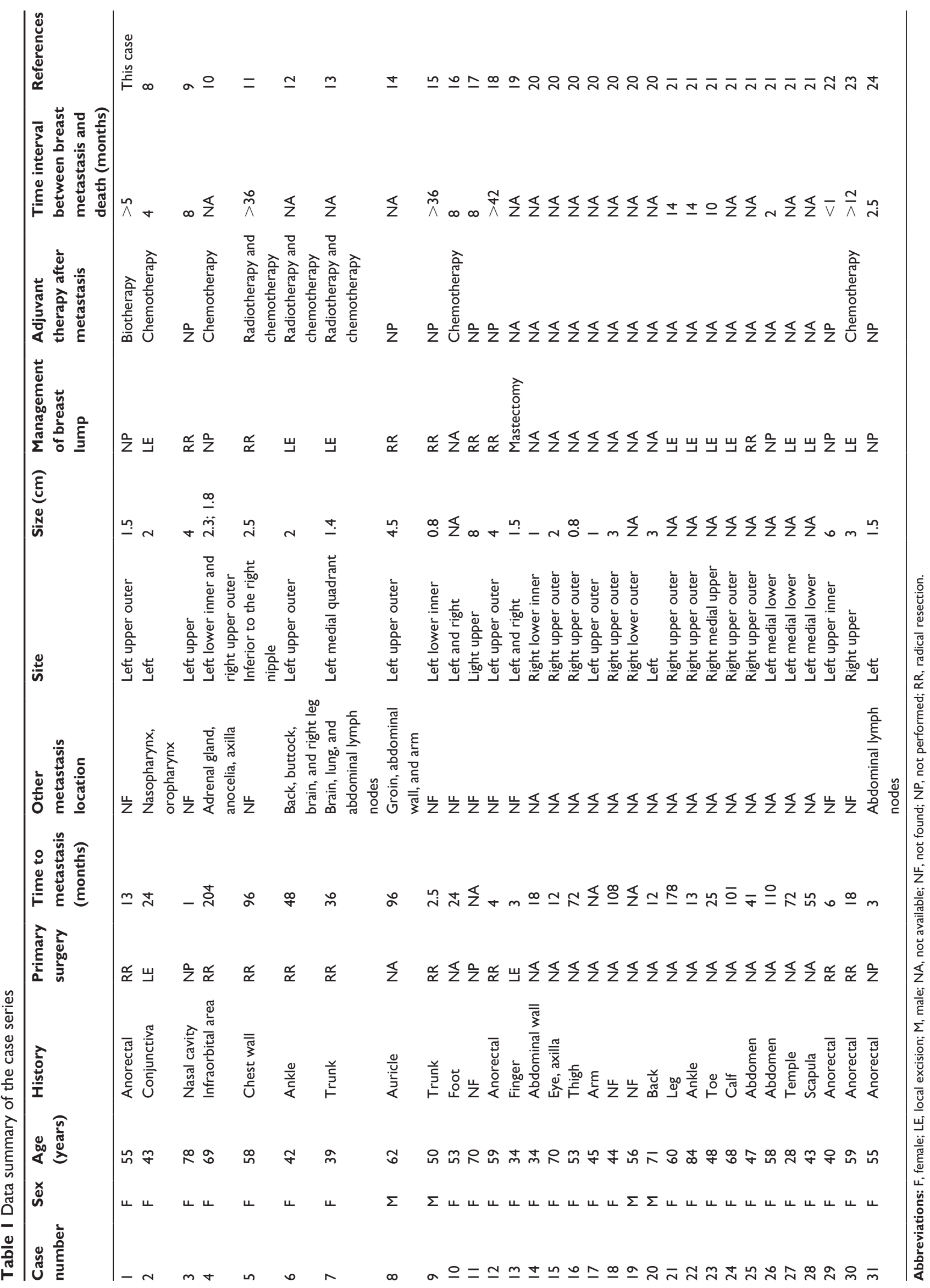


she has been followed-up for 5 months with no considerable changes in her condition.

\section{Conclusion}

Metastasis of tumors to the breast is a very rare phenomenon. The possibility of metastasis should be considered in the patients with a history of melanoma or other malignant tumors when masses are detected in the breast tissue. The patients with metastasis to the breast often demonstrate accompanying multiple metastases to other tissues and organs; therefore, a comprehensive examination and assessment of the conditions of the patients are necessary, as it might directly influence the prognostic assessment and the establishment of effective therapeutic approaches.

\section{Acknowledgments}

This work was supported by the Natural Science Foundation of Liaoning Province, People's Republic of China (numbers L2015598 and 201601968). The patient provided written informed consent for the publication of their data.

\section{Disclosure}

The authors report no conflicts of interest in this work.

\section{References}

1. Chang AE, Karnell LH, Menck HR. The National Cancer Data Base report on cutaneous and noncutaneous melanoma: a summary of 84,836 cases from the past decade. The American College of Surgeons Commission on Cancer and the American Cancer Society. Cancer. 1998;83(8):1664-1678.

2. Batus M, Waheed S, Ruby C, Petersen L, Bines SD, Kaufman HL. Optimal management of metastatic melanoma: current strategies and future directions. Am J Clin Dermatol. 2013;14(3):179-194.

3. Ishizone S, Koide N, Karasawa F, et al. Surgical treatment for anorectal malignant melanoma: report of five cases and review of 79 Japanese cases. Int J Colorectal Dis. 2008;23(12):1257-1262.

4. Slingluff CL Jr, Vollmer RT, Seigler HF. Anorectal melanoma: clinical characteristics and results of surgical management in twenty-four patients. Surgery. 1990;107(1):1-9.

5. Brady MS, Kavolius JP, Quan SH. Anorectal melanoma: a 64-year experience at Memorial Sloan-Kettering Cancer Center. Dis Colon Rectum. 1995;38(2):146-151.

6. Ravdel L, Robinson WA, Lewis K, Gonzalez R. Metastatic melanoma in the breast: a report of 27 cases. J Surg Oncol. 2006;94(2):101-104.

7. Kharmoum S, Mohamed M, Benhammane H, et al. Conjunctival melanoma metastatic to the breast: a case report. BMC Res Notes. 2014;7:621.

8. Tanaka S, Sato N, Fujioka H, et al. A case of solitary breast metastasis from malignant melanoma of the nasal cavity. Oncol Lett. 2012;4(5): 889-892.

9. Karaman N, Doğan L, Atalay C, Özaslan C. Bilateral breast metastasis as the first sign of recurrence of a cutaneous melanoma: a case report. Ulus Cerrahi Derg. 2013;29(3):147-149.

10. Carswell KA, Behranwala KA, Nerurkar A, Gerald PH. Breast carcinoma and malignant melanoma metastasis within a single axillary lymph node. Int Semin Surg Oncol. 2006;3:32.

11. Samaraee AA, Khout H, Barakat T, Fasih T. Breast metastasis from a melanoma. Ochsner J. 2012;12(2):149-151.
12. Moschetta M, Telegrafo M, Lucarelli NM, et al. Metastatic breast disease from cutaneous malignant melanoma. Int J Surg Case Rep. 2014;5(1): 34-36.

13. Kang BS, Kim SK. Malignant melanoma with metastasis to the male breast. Indian J Dermatol Venereol Leprol. 2014;80(6):566-568.

14. Uludag M, Citgez B, Ozkaya O, Sakiz D. In-transit metastasis of the breast region from malignant melanoma of the trunk. BMJ Case Rep. 2009;2009:733-745.

15. Prvulović N, Đilas-Ivanović D, Nikolin B, Stojiljković B. Melanoma metastatic to the breast: a report of an unusual case. Imag Oncol. 2011; 19:79-80.

16. Nalbant OA, Vural S, Keleş MC, Nalbant E, Kandiloğlu AI. Metastatic malignant melanoma of the breast: a case report. $J$ Breast Health. 2011;7(1):37-39.

17. Lee JFY, Leung KL, Leow CK, Lau WY. An unusual case of breast metastasis from an anorectal melanoma. Eur J Surg Oncol. 1999;25(25): $441-442$.

18. Ho LWC, Wong KP, Chan JHM, Chow LWC, Leung EYF, Leong L. MR appearance of metastatic melanotic melanoma in the breast. Clin Radiol. 2000;55(7):572-573.

19. Cangiarella J, Symmans WF, Cohen JM, Goldenberg A, Shapiro RL. Malignant melanoma metastatic to the breast. Cancer Cytopathol. 1998;84(3):160-162.

20. Loffeld A, Marsden JR. Management of melanoma metastasis to the breast: case series and review of the literature. Br J Dermatol. 2005; 152(6):1206-1210.

21. Joshi AR, Bavikar RR, Khande T. Metastasis of rare tumor at an usual site-a case report. J Cytol Histol. 2014;5:6.

22. Belbaraka R, Asabbane A, Hachi H, Elgueddari BK, Errihani H. Breast metastases from anorectal melanoma. J Med Cases. 2010; 293(2):168-174

23. Ozgüroglu M, Ozaras R, Tahan V, et al. Anorectal melanoma metastatic to the breast. J Clin Gastroenterol. 1999;29(2):197-199.

24. Lee YN. Better prognosis of many cancers in female: a phenomenon not explained by study of steroid receptors. J Surg Oncol. 1984;25(4): $255-262$.

25. Arora R, Robinson WA. Breast metastases from malignant melanoma. J Surg Oncol. 1992;50(1):27-29.

26. Mukherji B, Wilhelm SA, Guha A, Ergin MT. Regulation of cellular immune response against autologous human melanoma: I. Evidence for cell-mediated suppression of in vitro cytotoxic immune response. J Immunol. 1986;136(5):1888-1892.

27. Sakaguchi S, Sakaguchi N, Asano M, Itoh M, Toda M. Immunologic self-tolerance maintained by activated $\mathrm{T}$ cells expressing IL-2 receptor alpha-chains (CD25): breakdown of a single mechanism of self-tolerance causes various autoimmune diseases. J Immunol. 1995; 155(3):1151-1164.

28. Jayaraman P, Alfarano MG, Svider PF, et al. iNOS expression in CD4+ $\mathrm{T}$ cells limits Treg induction by repressing TGF $\beta 1$ : combined iNOS inhibition and Treg depletion unmask endogenous antitumor immunity. Clin Cancer Res. 2014;20(24):6439-6451.

29. Janni W, Rack B, Sommer H, et al. Intra-mammary tumor location does not influence prognosis but influences the prevalence of axillary lymphnode metastases. J Cancer Res Clin Oncol. 2003;129(9):503-510.

30. Gershenwald JE, Thompson W, Mansfield PF, et al. Multi-institutional melanoma lymphatic mapping experience: the prognostic value of sentinel lymph node status in 612 stage I or II melanoma patients. J Clin Oncol. 1999; 17:976-983.

31. Vizcaino I, Torregrosa A, Higueras V, et al. Metastases to the breast from extramammary malignancies: a report of four cases and review of literature. Eur Radiol. 2001;11(9):1659-1665.

32. Amiehetti M, Perani B, Boi S. Metastases to the breast from extramammary malignancies. Oncology. 1990;47(3):257-260.

33. McCrea ES, Johnston C, Haney PJ. Metastases to the breast. AJR Am J Roentgenol. 1983;141(4):685-690. 


\section{Publish your work in this journal}

OncoTargets and Therapy is an international, peer-reviewed, open access journal focusing on the pathological basis of all cancers, potential targets for therapy and treatment protocols employed to improve the management of cancer patients. The journal also focuses on the impact of management programs and new therapeutic agents and protocols on

patient perspectives such as quality of life, adherence and satisfaction. The manuscript management system is completely online and includes a very quick and fair peer-review system, which is all easy to use. Visit http://www.dovepress.com/testimonials.php to read real quotes from published authors.

Submit your manuscript here: http://www.dovepress.com/oncotargets-and-therapy-journal 